\title{
A Study on Application of the Korea Human Scale to Anthropometric Design
}

\author{
Dhong Ha Lee \\ Department of Industrial Engineering, The University of Suwon, Suwon, 445-743
}

\begin{abstract}
Objective: The aim of this study is to show a correct application procedure using the compact Korean anthropometric data application program called Korean Human Scale(KHS) for anthropometric design. Background: The nation-wide anthropometric survey project called 'Size Korea' developed KHS and distributed it to the public on the web site. But some insufficiency of the current web service of KHS misleads the users; they just put their own statue and pick up a meaningless data for a body dimension. Method: This study provides five steps to follow to read appropriate data from KHS for an anthropometric design. Results: As a case study, the depth dimension of the supervisory and control console used in the Korea nuclear power plant was determined following the procedure and compared with the console design guideline recommendation. Conclusion: The supplementary anthropometry table should be added on the web service of KHS for users to read a meaningful data for design. Application: If properly used, the KHS has a lot more potential application area than users can expect such as in control center design area.
\end{abstract}

Keywords: Korea human scale, Body measurement dimensions, Anthropometry data, Depth of console design

\section{Introduction}

Size Korea의 직접측정 프로젝트는 한국인의 정밀한 신체 제원을 수집하기 위하여 2003 2004년 동안 15,576명의 전국 표본 인원에 대하여 각 피측정자 별로 125 부위의 인체 치수를 측정하고 이를 테이블 형태로 보고서에 기록하였다 (Korean Agency for Technology and Standards, 2005). 수집된 통계치는 너무 방대하므로 인체계측자료를 설계에 적용하려는 설계자가 보고서 형태로 참조하기가 불편하다. 이러한 문제점을 극복하기 위해 Jeong(2004)은 인체자료 참조를 위한 인체계측자료에 대한 인터페이스를 연구하였 다. Jeong(2004)은 제품설계자가 쉽게 인체자료를 참조하 는 방법으로 자료를 스케일화한 시각적 도구인 휴먼스케일을 개발하였다. 이전에 개발된 휴먼스케일(Niels et al., 1991) 은 키를 중심으로 인체치수를 검색할 수 있었지만 Jeong
(2004)이 개발한 휴먼스케일은 키와 사용자 집단의 연령대 를 통해 필요한 인체치수를 검색할 수 있다는 것이 특징이다. Jeong (2004)의 휴먼스케일은 총 119 개 인체부위에 대한 치 수를 제공한다(Table 1 ).

Table 1. Number of body measurement dimensions of the Human Scale by Jeong(2004)

\begin{tabular}{l|c}
\hline Body postures or body parts & No. of dimensions \\
\hline Standing posture, front and rear view & 33 \\
\hline Standing posture, side view & 45 \\
\hline Sitting posture, front and side view & 20 \\
\hline Head, front and side view & 8 \\
\hline Hand & 9 \\
\hline Foot & 4 \\
\hline Total & 119 \\
\hline
\end{tabular}

Corresponding Author: Dhong Ha Lee. Department of Industrial Engineering, The University of Suwon, Suwon, 445-743. 
Jeong (2004)은 휴먼스케일의 보급 방식으로 컴퓨터를 통한 디지털 방식과 수치 원판으로 구성된 아날로그 방식을 제안하였다. 이 중 아날로그 방식의 휴먼스케일은 일반인이 사용하기에 다음과 같은 한계를 가진다.

- 모형의 크기가 제한되고 표현자료의 방대함으로 인해 표현 되는 숫자의 폰트 크기가 작아서 가시성에 문제가 있다.

- 제작상의 어려움으로 인해 회전 수치 원판과 표시 창이 정 확히 맞도록 제작하기 위한 제작비가 많이 든다.

- 총 6 면으로 된 도면을 3장으로 나누어 제작하여 휴대 시 불편함이 따른다.

- 인체자료가 업데이트 될 경우 수치 원판을 재제작해야 한다.

- 사용 환경에 따라 휴먼스케일 제품 수명이 제한된다.

아날로그 방식의 휴먼스케일은 이를 컴퓨터 프로그램으로 전환하면 단점의 대부분을 보완할 수 있다. Lee(2006)는 Jeong (2004) 의 휴먼스케일 모형을 C++ 언어를 사용하여 컴퓨터 프로그램으로 개발하였다. 컴퓨터 프로그램으로 된 휴먼스케일 모형은 다음과 같은 장점을 지닌다.

- 모형의 크기가 컴퓨터 모니터 화면 크기로 확대되어 표현 되는 숫자의 가시성이 향상된다.

- 인체자료가 업데이트 될 경우 휴먼스케일에 표시되는 자료 를 쉽게 변경할 수 있다.

- 수명이 영구적이다.

- 제작 비용 및 유지보수 비용이 아날로그 방식에 비해 저 렴하다.

디지털 방식의 휴먼스케일은 Size Korea Home Page (2011)에서 누구나 접속하여 사용할 수 있도록 Korea Human Scale(KHS) 라는 이름의 웹 응용프로그램으로 서비 스되고 있다(Figure 1). 현재는 사용자의 키를 입력하여 관 련된 인체치수를 검색하는 방식으로만 활용되고 있다. 그런 데 출력되는 인체치수는 입력되는 키의 퍼센타일에 해당하 는 인체치수인데 이에 대한 정확한 사용 가이드가 없이 서 비스되고 있는 실정이다. 올바른 사용 가이드가 제공된다면 $\mathrm{KHS}$ 는 훨씬 더 다양한 용도로 활용될 수 있다. 본 연구에 서는 디지털 방식의 $\mathrm{KHS}$ 를 실제 디자인에 활용할 수 있도 록 올바른 절차를 제시하였다.

\section{Application Procedure using KHS for Anthropometric Design}

$\mathrm{KHS}$ 를 사용하여 필요한 인체계측자료를 검색하고 이를

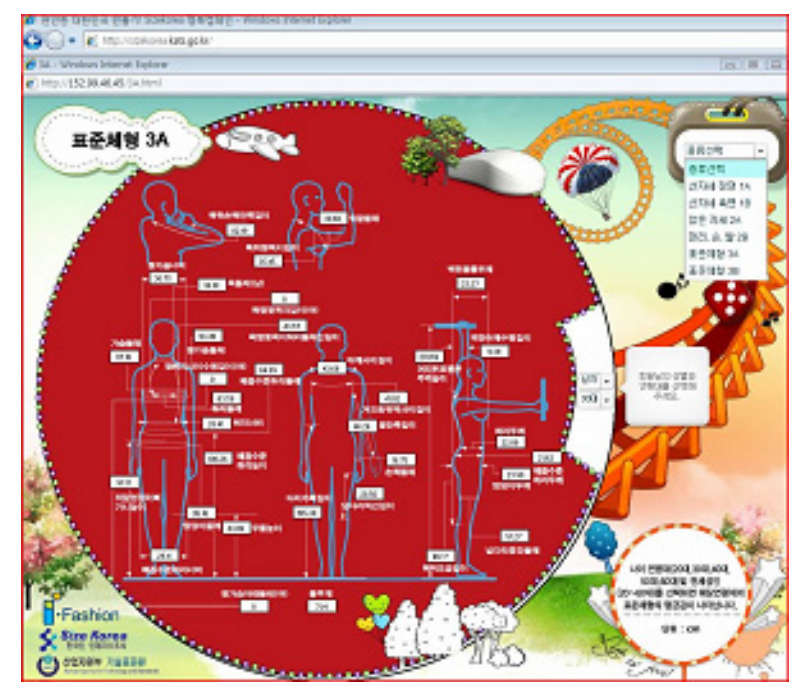

Figure 1. Korea Human Scale(KHS) on the Web (http://sizekorea.kats.go.kr)

제품 설계나 작업장 설계에 적용하는 일반적 절차는 다음과 같다 (Jeong and Lee, 2009).

단계 1 : 디자인과 관련되어 어떤 인체치수가 필요한지를 결 정한다.

단계 2: 디자인을 사용할 집단을 정의한다.

단계 3: 적용할 인체치수 적용 원칙을 결정한다.

단계 4: KHS로부터 관련 치수를 읽는다.

단계 5: 단계 4에서 읽은 자료를 착용복장을 위한 여유치수 로 보정한다.

\subsection{Step 1: Select the anthropometric variables appro- priate for the design}

이 단계에서는 디자인 문제에서 가장 중요한 역할을 하는 인체계측변수가 무엇인가를 결정한다. 작업대, 의자, 가구, 각종 수공구, 의복, 주거 공간, 자동차 인테리어 등 사람이 직접 접촉하는 거의 모든 대상이 인체치수 자료에 맞추어 설 계해야 할 대상이다. 이들 설계 대상은 인체가 접촉하는 부 위에 따라 적용하는 인체계측변수가 달라진다. 예를 들어 출입문의 크기를 결정하는데는 키와 윗팔사이너비를 인체계 측변수로 선정한다. 잠옷의 경우 키, 가슴둘레 또는 허리둘 레 등을 인체계측변수로 선정한다.

\subsection{Step 2: Define target user group for the design}

이 단계에서는 디자인을 사용할 집단의 성별, 연령대, 디 자인이 수용할 수 있는 사용자 집단의 범위를 결정한다. 사 
람의 신체적 특성은 인종적, 문화적 배경의 차이에 따라 다 르며 성별, 나이, 영양상태, 건강상태, 임신상태, 장애 여부에 따라서도 달라진다. 하나의 설계에 의해 모든 사람을 만족시 킬 수 없으므로 제품을 사용할 주요 목표 집단을 설정해야 한다. 목표 집단을 정하는 과정에서는 다음과 같은 질문이 도움이 된다.

- 누가 이 제품을 사용하는가?

- 제품이 어디서 팔리며 어디서 사용되는가?

- 향후 이 제품의 판매시장을 어디로 확대할 수 있는가?

$\mathrm{KHS}$ 의 적용 인종은 한국인으로 제한되어 있다. $\mathrm{KHS}$ 를 적용하기 위해 추가로 결정해야 할 사용자 집단 분류로는 성 별, 연령대가 있다. KHS에서 제공하는 인체치수 통계자료의 성별 및 연령대 분류는 Table 2 와 같다.

Table 2. KHS shows body measurement dimensions by gender and age group

\begin{tabular}{c|l|l}
\hline Age group & \multicolumn{1}{|c}{ Male } & \multicolumn{1}{c}{ Female } \\
\hline $\begin{array}{c}0.5,1,2, \\
\ldots, 15(\mathrm{yr})\end{array}$ & $\begin{array}{l}\text { Head, hand and foot } \\
\text { dimensions(in mean) }\end{array}$ & $\begin{array}{l}\text { Head, hand and foot } \\
\text { dimensions(in mean) }\end{array}$ \\
\hline $\begin{array}{c}\text { All adult } \\
\text { group }\end{array}$ & $\begin{array}{l}\text { Standing, sitting head, } \\
\text { hand and foot dimensions } \\
\text { (in mean and percentile) }\end{array}$ & $\begin{array}{l}\text { Standing, sitting head, } \\
\text { hand and foot dimensions } \\
\text { (in mean and percentile) }\end{array}$ \\
\hline $20 \mathrm{~s}$ & $\begin{array}{l}\text { Standing, sitting, hand and } \\
\text { foot dimensions(in mean) }\end{array}$ & $\begin{array}{l}\text { Standing, sitting, hand and } \\
\text { foot dimensions(in mean) }\end{array}$ \\
\hline $30 \mathrm{~s}$ & $\begin{array}{l}\text { Standing, sitting, hand and } \\
\text { foot dimensions(in mean) }\end{array}$ & $\begin{array}{l}\text { Standing, sitting, hand and } \\
\text { foot dimensions(in mean) }\end{array}$ \\
\hline $40 \mathrm{~s}$ & $\begin{array}{l}\text { Standing, sitting, hand and } \\
\text { foot dimensions(in mean) }\end{array}$ & $\begin{array}{l}\text { Standing, sitting, hand and } \\
\text { foot dimensions(in mean) }\end{array}$ \\
\hline $50 \mathrm{~s}$ & $\begin{array}{l}\text { Standing, sitting, hand and } \\
\text { foot dimensions(in mean) }\end{array}$ & $\begin{array}{l}\text { Standing, sitting, hand and } \\
\text { foot dimensions(in mean) }\end{array}$ \\
\hline $60 \mathrm{~s}$ & $\begin{array}{l}\text { Standing, sitting, hand and } \\
\text { foot dimensions(in mean) }\end{array}$ & $\begin{array}{l}\text { Standing, sitting, hand and } \\
\text { foot dimensions(in mean) }\end{array}$ \\
\hline
\end{tabular}

\subsection{Step 3: Determine the application principles of anthropometric data}

디자인에 인체치수를 적용하는 원칙으로는 조절식 설계, 극단치 기준 설계, 평균치 기준 설계가 있다(Sanders and McCormick, 1992). 인체치수를 적용하는 원칙에 따라 적 용되는 인체치수가 달라진다.

단계 3 에서는 적용 원칙으로 조절식 설계, 극단치 기준 설계, 및 평균치 기준 설계 중에서 하나를 선택한다(Jeong and Lee, 2009). 제품이나 작업장 설계에서 가장 바람직한 설계방법은 조절식 설계이다. 조절식 설계 개념에 의한 설계 치수는 사용자 그룹 중에서 작은 사람의 치수에서 큰 사람
의 치수까지를 포함할 수 있도록 여자 5퍼센타일에서 남자 95퍼센타일 값을 조절범위로 사용한다.

특정 제품이나 설비를 설계할 때 어떤 인체 특성의 한 극 단에 속하는 사람을 대상으로 설계하면 그 집단의 거의 모 든 사람을 수용할 수 있는 경우가 있다. 이 경우에는 작거나 큰 사람의 치수를 이용하여 설계를 한다. 이 경우에 일반적 으로 여자 5퍼센타일이나 남자 95퍼센타일이 설계 기준이 된다.

조절식이 허용되지 않고 최대치수나 최소치수가 이 치수 와 가깝지 않은 집단의 대다수에게 심각한 불편을 줄 경우 에는 평균치를 적용한다. 인체치수는 정규분포를 하므로 평 균치 주위에 분포하는 사람들의 빈도가 다른 치수에 비해 상대적으로 높다는 사실에 착안한 설계 개념이다. $\mathrm{KHS}$ 에 서는 성별 및 다양한 연령대별로 퍼센타일과 평균치(표준 치수)를 6 개의 슬라이드에 나누어 제공하므로(Figure 2) 필 요한 퍼센타일이나 평균치를 해당 슬라이드에서 찾아야 한 다. 인체치수 적용원칙에 따른 $\mathrm{KHS}$ 슬라이드 탐색 절차는 Figure 2와 같다.

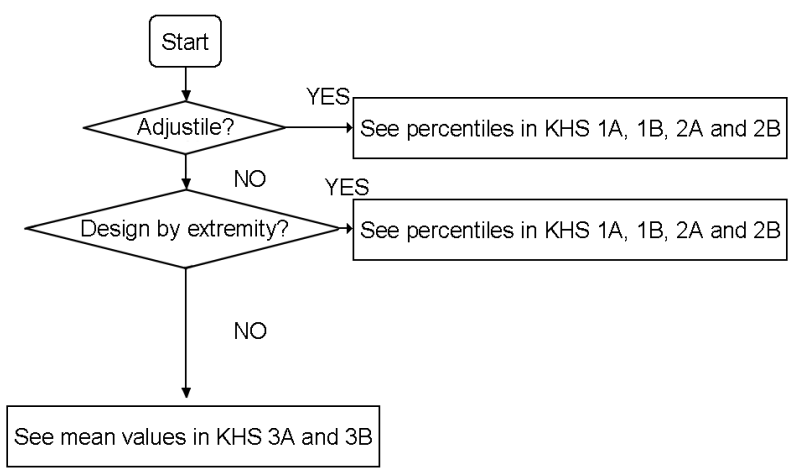

Figure 2. Selection procedure for the slides of KHS

\subsection{Step 4: Read anthropometric data on the slides of KHS}

$\mathrm{KHS}$ 로부터 필요한 치수를 읽기 위해서는 단계 1 에서 결 정한 인체계측변수가 있는 슬라이드 $(1 \mathrm{~A}-3 \mathrm{~B})$ 를 드롭다운리 스트를 통해 선택하고(Figure 3) 단계 2에서 결정한 디자인 사용 집단의 성별, 연령대 및 단계 3 에서 결정한 퍼센타일을 입력한다.

$\mathrm{KHS} 1 \mathrm{~A}$ 와 $1 \mathrm{~B}$ 슬라이드에는 선 자세에서 측정된 77 개 인체계측변수에 대한 퍼센타일이 표시되어 있다. KHS $2 \mathrm{~A}$ 슬라이드에는 앉은 자세에서 측정된 20개 인체계측변수에 대한 퍼센타일이 표시되어 있다. KHS $2 \mathrm{~B}$ 슬라이드에는 머 리, 손, 발 부위로부터 측정된 21 개 인체계측변수에 대한 평 
균값(0.5 15세 연령대)과 퍼센타일(성인 연령대)이 표시되 어 있다. KHS $3 \mathrm{~A}$ 와 $3 \mathrm{~B}$ 슬라이드에는 표준체형의 선 자세와 앉은 자세로부터 측정된 65 개 인체계측변수에 대한 평균치 가 표시되어 있다(Table 3).

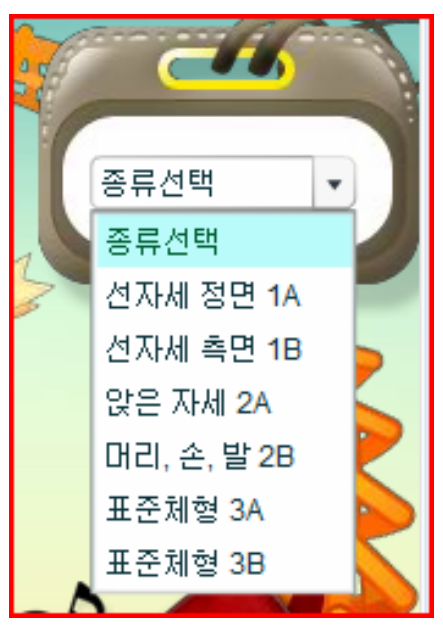

Figure 3. Drop down list for slides provided by KHS

Table 3. Body measurement dimensions provided by KHS slides(excerpts)

\begin{tabular}{c|l}
\hline KHS screen & Body measurement dimension \\
\hline \multirow{4}{*}{ 1A } & Waist height \\
\cline { 2 - 2 } & Knee height \\
\cline { 2 - 2 } & Iliac spine height \\
\hline \multirow{4}{*}{ 1B } & Overhead fist reach \\
\cline { 2 - 2 } & Eye height \\
\cline { 2 - 2 } 2A & Cervical height \\
\hline \multirow{4}{*}{ 2B } & Sitting height \\
\cline { 2 - 2 } & Eye height, sitting \\
\hline & Cervicale height, sitting \\
\cline { 2 - 2 } & Head length \\
\cline { 2 - 2 } & Head breadth \\
\hline \multirow{4}{*}{ 3A } & Head height \\
\cline { 2 - 2 } & Overhead fist reach \\
\cline { 2 - 2 } & Waist depth \\
\hline & Body depth, standing \\
\hline \multirow{4}{*}{ 3B } & Sitting height \\
\hline & Shoulder height, sitting \\
\cline { 2 - 2 } & Foot length \\
\hline
\end{tabular}

\subsection{Step 5: Add allowances for clothing}

$\mathrm{KHS}$ 에서 제공하는 인체치수는 옷을 벗은 상태로 측정된 치수이므로 의복, 신발, 헬멧 또는 장갑을 착용하고 제품을 사용하는 사람을 대상으로 하는 디자인에서는 이들에 대한 여유치수를 더하여야 한다. 예를 들면 구두를 신은 성인 남 자 집단에 대해서는 $\mathrm{KHS}$ 에서 제공하는 키 값에 $2.5 \mathrm{~cm}$ 를 추가해야 한다(Pulat, 1992).

\section{A case Study for Application of KHS}

원자력 발전소의 계측 제어 시스템 중 감시제어반의 콘솔 은 운전원들의 인체치수에 적합하게 설계해야 하는 중요 시 스템 중의 하나이다. 1992 년도 측정된 제 3 차 인체치수조사 과정에서 측정된 자료를 기반으로 한 감시제어반 설계지침 (Korea Power Engineering Company, 1999)에는 감시제 어반 콘솔의 작업판(bench board) 깊이(depth)를 $72 \mathrm{~cm}$ 로 규정하였다(Korea Power Engineering Company, 1999). 본 연구에서는 2005 년도에 측정된 인체치수를 감시제어반 콘솔의 작업판 깊이 설계에 적용하기 위하여 $\mathrm{KHS}$ 를 활용하 고 상기 절차를 적용하였다.

\subsection{Step 1: Select the anthropometric variables appro- priate for the design}

감시제어반 콘솔의 작업판 깊이를 결정하는데 가장 중요 한 역할을 하는 인체계측변수는 팔길이 + 손직선길이가 될 것이다.

\subsection{Step 2: Define target user group for the design}

본 연구에서는 감시제어반 콘솔을 사용할 집단의 성별, 연 령대, 디자인이 수용할 수 있는 사용자 집단의 범위를 다음 과 같이 임의로 가정하였다.

성별: 남자 집단

연령대: 20대

모집단 수용범위: $95 \%$

\subsection{Step 3: Determine the application principles of anthropometric data}

디자인에 적용할 인체치수 적용원칙을 조절식 설계, 극단 치 기준 설계, 및 평균치 기준 설계 중에서 결정한다. 감시제 
어반 콘솔의 작업판 깊이는 조절식 설계가 불가능하다. 감시 제어반 콘솔의 작업판의 깊이는 작은 사람을 기준으로 설계 하면 큰 사람도 수용할 수 있으므로 극단치 기준 설계 중 최소치수를 적용해야 한다. 구해야 할 인체치수는 20 대 남 성 5 퍼센타일 팔길이 +20 대 남성 5 퍼센타일 손직선길이 가 될 것이다.

\subsection{Step 4: Read anthropometric data on the slides of KHS}

인체계측변수 중 팔길이에 관한 자료는 $\mathrm{KHS} 1 \mathrm{~B}$ 에 표시 되어 있다. KHS IB 슬라이드에는 구하려는 인체치수의 퍼 센타일에 해당하는 키값을 입력하여야 한다. 따라서 남자 5 퍼센타일 팔길이를 구하기 위해서는 남자 5퍼센타일 키를 입력해야 하는데 현재 KHS가 서비스되고 있는 사이즈코리 아 웹사이트에는 Table 4와 같은 키의 주요 퍼센타일 자료 를 웹에서 쉽게 검색할 수 있는 형태로 제공하지 않는다. 따라서 본 연구에서는 인체치수 자료집(KATS, 2005; Lee 2006)에서 Table 4에 해당하는 자료를 찾아 남자 5퍼센타 일 정수 근사값 $(166 \mathrm{~cm})$ 을 Figure 4 와 같이 KHS $1 \mathrm{~B}$ 슬라

Table 4. Percentiles of statue (Korean male and female in the age of 20s)

\begin{tabular}{c|c|c}
\hline Percentile & Male $(\mathrm{cm})$ & Female $(\mathrm{cm})$ \\
\hline 0.05 & 165.81 & 153.29 \\
\hline 0.25 & 170.15 & 157.25 \\
\hline 0.5 & 173.17 & 160.01 \\
\hline 0.75 & 176.18 & 162.76 \\
\hline 0.95 & 180.52 & 166.73 \\
\hline
\end{tabular}

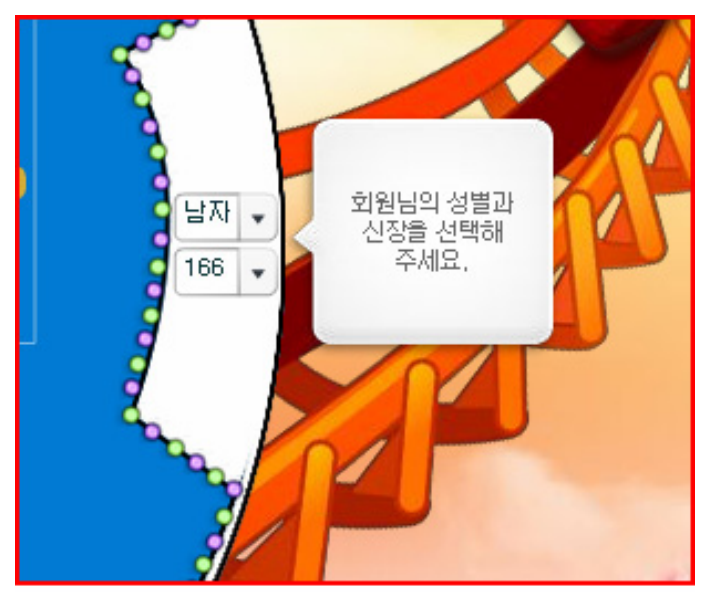

Figure 4. Selection of male 5th percentile statue on the KHS slide $1 \mathrm{~B}$
이드에 입력하였다.

Figure 5에서 보는 바와 같이 KHS $1 \mathrm{~B}$ 슬라이드에서 확 인한 남자 5 퍼센타일 팔길이는 $56.04 \mathrm{~cm}$ 가 된다.

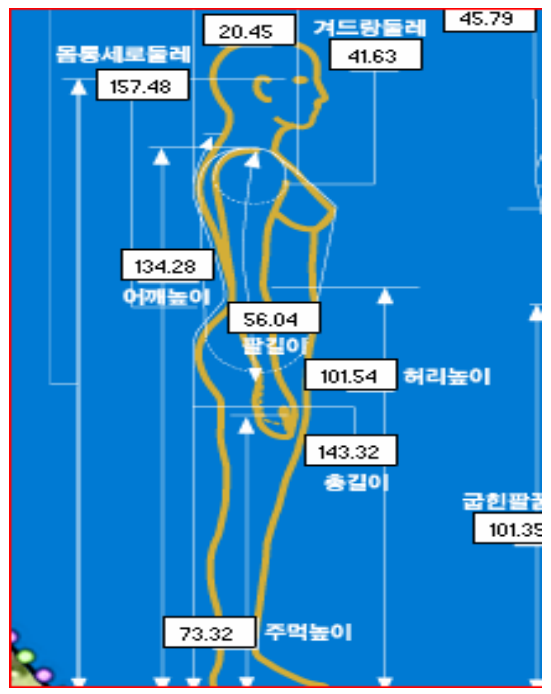

Figure 5. KHS screen1B showing the 5 th percentile of Korean male arm length $(56.04 \mathrm{~cm})$

인체계측변수 중 20 대 남자 5 퍼센타일 손직선길이에 관한 자료는 KHS $2 \mathrm{~B}$ 슬라이드에서 구할 수 있다. KHS $2 \mathrm{~B}$ 슬라 이드는 머리, 손, 발에 관한 치수에 대해 성장기 남녀를 위 해서는 연령대별 평균치를 제공하고 성장이 완료된 성인에 대해서는 대표적인 퍼센타일 $(1,5,10,25,50.75,90,95$, 99 percentile)을 제공한다. 성인 남자 5퍼센타일 손직선 길이를 구하기 위해서는 Figure 6과 같이 남자 5퍼센타일

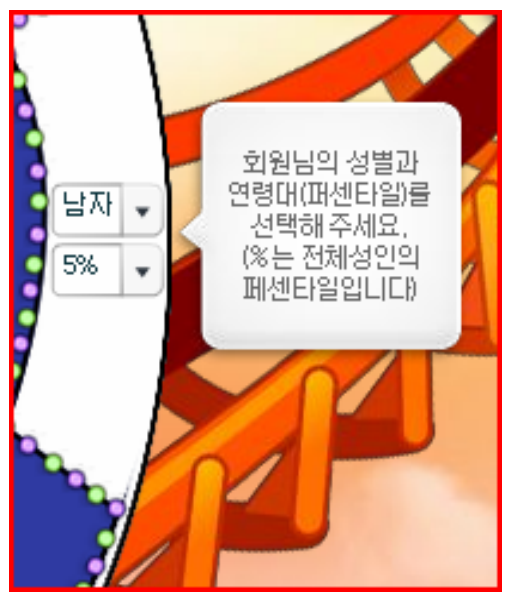

Figure 6. Selection of adult male 5th percentile on the KHS slide 2B 
을 선택하고 Figure 7 과 같이 손직선길이 표시상자에서 $17.46 \mathrm{~cm}$ 를 읽는다.

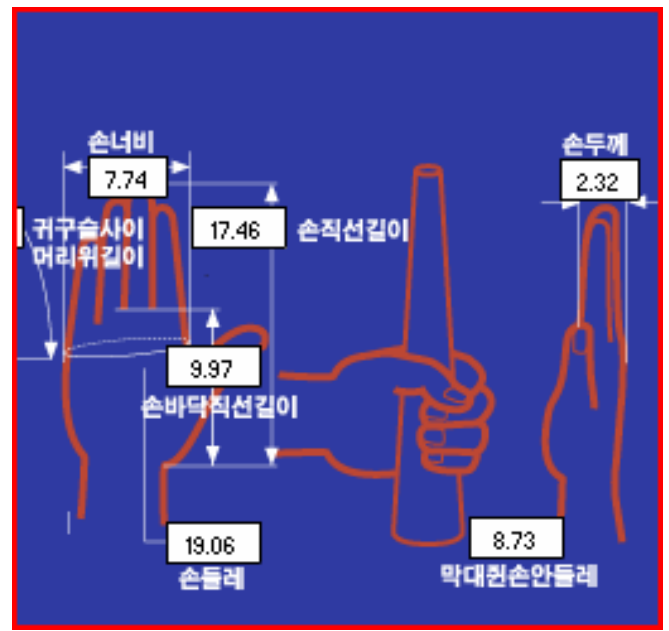

Figure 7. KHS screen 2B showing the 5th percentile of Korean male hand length $(17.46 \mathrm{~cm})$

\subsection{Step 5: Add allowances for clothing}

원자력 발전소의 감시제어반 콘솔에서는 맨손으로 작업하 는 경우가 대부분이므로 장갑이나 의복 착용에 따른 보정은 하지 않아도 된다. 따라서 감시제어반 콘솔의 작업판 깊이는 $56.0+17.5=73.5 \mathrm{~cm}$ 를 기준으로 설계할 것을 추천할 수 있다.

1992년에 측정된 제 3 차 인체치수조사에서 측정된 자료 를 기반으로 한 감시제어반 설계지침의 콘솔 깊이 추천치 $72 \mathrm{~cm}$ 에 비해 $1.5 \mathrm{~cm}$ 증가된 것을 알 수 있다. 이는 2005 년과 1992 년 사이에 변화된 전반적인 국민 체위의 향상에 기인한 것으로 추정할 수 있다.

\section{Conclusion}

본 연구에서는 기존의 아날로그형 휴먼스케일을 컴퓨터 응용프로그램으로 전환하여 웹을 통하여 사용할 수 있는 $\mathrm{KHS}$ 를 디자인에 활용하는 절차를 개발하였다. KHS를 올바 르게 디자인에 적용하기 위해서는 Table 4 와 같은 키에 대 한 대표적인 퍼센타일 표를 제공하는 것이 필요한데 이는 사이즈코리아의 웹사이트에서 시급히 보완되어야 할 부분 이다.

$\mathrm{KHS}$ 를 올바르게 활용하면 본 연구의 사례연구에서 제안
한 사례 이외에도 다양한 설계 제원을 결정하는데 사용할 수 있다(Lee, 2006). 이외에도 KHS는 다음과 같은 기대 효과 를 가지고 있다.

- 인체계측자료 적용이 필요한 현장 설계자들이 웹에 접속하 여 쉽게 참조할 수 있다.

- 인테리어, 작업 공간, 사무용 가구, 일상용품, 의류 등 설계 에 필수적인 한국인 신체자료를 범국민적으로 보급할 수 있다.

- 신속한 자료 갱신을 통해 최신의 한국인 신체자료를 제공 할 수 있다.

사이즈코리아 프로젝트는 이미 2010년에 제6차 인체치 수 측정사업을 통해 한국인 인체치수를 갱신한 바 있다 $(\mathrm{Yu}$, 2010). 현재 사이즈코리아 홈페이지를 통하여 서비스되고 있는 $\mathrm{KHS}$ 는 제 5 차 인체치수 측정사업을 통해 획득된 자료 를 바탕으로 하고 있으므로 $\mathrm{KHS}$ 의 배경자료를 제 6 차 자료 로 갱신하는 것이 차후의 과제가 될 것이다.

\section{Acknowledgements}

This work was funded by grants from Korean Agency for Technology and Standards.

\section{References}

Jeong, B. Y. and Lee, D. K., Modern Ergonomics, 2nd Ed., Minyoeng Publishing Co, 2009.

Jeong, E. S., A Study on Development of a Human Scale for Visual Illustration of Korean Anthropometric Data, Technical Report of KATS, 2004.

Korea Power Engineering Company, Human Factors Engineering Guideline Document, 9-750-J410 (HF010), Rev 1, 1999.

Korean Agency for Technology and Standards (KATS), The 5th Korean Anthropometry Survey Data-Anthropometric Statistics by Direct Measurement, Technical Report, 2005.

Lee, D. H., Development of the Digital Korea Human Scale and the Application Manual, Technical Report of KATS, 2006.

Niels D., Alvin R. T., David H., Humanscale 1-9 Manual, Henry Dreyfuss Associates, 1991.

Pulat B. M., Fundamentals of Industrial Ergonomics, Prentice Hall, 1992.

Sanders, M. S. and McCormick, E. J., Human Factors in Engineering and Design, 7th Ed, McGraw-Hill, 1992.

Size Korea Home Page, http://sizekorea.kats.go.kr(retrieved December 1, 2011). 
Yu, J. W., The 6th Korean Anthropometry Direct Measurement Survey Project Report, Technical Report of KATS, 2010.

\section{Author listings}

Dhong Ha Lee: dhonghal@suwon.ac.kr

Highest degree: PhD, Department of Industrial Engineering, KAIST

Position title: Professor, Department of Industrial Engineering, the

University of Suwon

Areas of interest: Human Factors in Nuclear Power Plant, Risk

Management, $\mathrm{HCI}$
Date Received : 2011-12-23

Date Revised :2012-01-11

Date Accepted : 2012-01-11 